\title{
A gentle reminder
}

\author{
David A. Bloom
}

Received: 25 January 2010 / Accepted: 9 February 2010/Published online: 10 March 2010

(C) Springer-Verlag 2010

As we have all come to appreciate, there are many reasons for reading a journal article. For many, it is a way of learning about a topic, and yet for others, it is a way of confirming what is already known by the reader. I, on occasion, use journal articles to see what my contemporaries, colleagues, and friends are writing about - what puts the "wind in their sails." Earning continuing education credits, formulating research ideas, and learning from different writing styles are all benefits that come from reading an original article, review, pictorial essay, or case report. Yet the one for me that trumps them all is the "gentle reminder," namely the article that reminds me of an important concept I once knew, still tucked in the back of my memory, but one I do not see often enough to have at the ready. In other words, it's the one I might miss without the "gentle reminder."

The article titled "Congenital esophageal stenosis associated with esophageal atresia/tracheoesophageal fistula: clinical and radiologic features," by Yoo and colleagues [1], falls easily into this last category. I am sure that some of you have had a case of congenital esophageal stenosis (CES) with esophageal atresia/tracheoesophageal fistula (EA/TEF) in which you saw the finding, did a literature search or showed a colleague, and followed up with the pediatric surgeon to see what the lesion turned out to be. I clearly remember a case from my fellowship, with the subsequent noon conference discussion about complete cartilaginous rings/tracheobronchial remnants as one cause of the distal stenosis. And I recall another case 10 years later, where CES was at first called a reflux stricture in a 2-year-old after neonatal repair of EA/TEF, with unsuccessful balloon dilatation and subsequent esophageal perforation after bougienage,

D. A. Bloom $(\bowtie)$

Section of Pediatric Radiology, Beaumont Children's Hospital, Department of Radiology, William Beaumont Hospital,

3601 West 13 Mile Road,

Royal Oak, MI 48073, USA

e-mail: david.bloom@beaumont.edu where in retrospect the limited postoperative esophagram at day 7 of life suggested a distal esophageal stricture (usually too young to have already developed a reflux stricture). Then 4 years after that, there was a child with a congenital esophageal stenosis suggested by postoperative esophagram who we are currently following as there are no clinical symptoms (mild distal esophageal narrowing by routine screening esophagram looking for post-anastamotic stricture).

Now we are presented with the "gentle reminder"- that congenital esophageal stenosis is associated with EA/TEF (12\% of patients in the current article), and that CES is frequently symptomatic ( $45 \%$ of the CES cases in this series) and often fails balloon dilatation, the standard of care for reflux strictures. Mostly, for me, this article reminds me that one has an invaluable opportunity to study the distal esophagus in patients with EA/TEF at the first postoperative esophagram. We are so focused on looking for anastamotic leaks and recurrent/residual tracheoesophageal fistulae that we may lose sight of the fact that there can be anomalies of the remaining distal esophagus. Even in patients who are to undergo delayed repair, with either temporizing proximal esophageal pouch decompression by an enteric tube or cervical esophagostomy, fistula takedown and gastrostomy tube insertion, evaluation of the distal esophagus can be performed safely and effectively. By performing a gastrostomy tube study, one may be able to reflux the distal esophagus to look for CES. The opportunity is there, if we remember to take it. Our patients will be the true beneficiaries. To Dr. Yoo and colleagues, thank you for the "gentle reminder."

\section{Reference}

1. Yoo HJ, Kim WS, Cheon J-E et al (2010) Congenital esophageal stenosis associated with esophageal atresia/tracheoesophageal fistula: clinical and radiologic features. Pediatr Radiol 40: doi: 10.1007/ s00247-010-1603-0 